\title{
Caracterização química e granulométrica de solos do Golfão maranhense
}

\author{
Gustavo Souza VALLADARES ${ }^{1}$
}

RESUMO

A área de estudo corresponde aos campos flúvio-marinhos com risco de inundação e presença de solos hidromórficos da região do Golfão Maranhense. Os solos dessa região apresentam algum impedimento a drenagem, proximidade com o mar (fonte de sais), condiçóes favoráveis a inundação e aos processos de evaporação. Este conjunto de fatores pode elevar as concentraçóes de sais solúveis e inviabilizar ou reduzir a produtividade. Foram coletadas 38 amostras de solo em 22 pontos com trado holandês a profundidades variáveis, normalmente de 0 a 20 e de 30 a $50 \mathrm{~cm}$. As amostras foram secas ao ar e analisados atributos químicos e granulométricos. Os solos do golfão maranhense apresentam grande variabilidade e predominam os com argila de atividade alta, alta soma de bases e altos teores de hidrogênio e alumínio. Os teores de magnésio são predominantes em relação aos de cálcio. Apesar da maioria dos solos apresentarem textura argilosa a granulometria é bastante variável. Mesmo com altos teores de magnésio e de sódio o grau de floculação das amostras pode ser considerado alto. Os solos do Golfão Maranhense não se encontram salinizados, porém é necessário manejá-los de maneira adequada para não promover sua salinização.

PALAVRAS-CHAVE: solo hidromórfico, planícies inundáveis, argila de atividade alta.

\section{Chemical and granulometric caracterization of soils in the Golfão Maranhense}

\section{ABSTRACT}

The study area of this study corresponds to fluviomarine fields with flood risk and the presence of hydromorphic soils in the Golfão Maranhense region. The soils of the area present slow drenage, proximity with the sea (salt source) and favorable conditions for flood, and evaporation processes. All these factors may increase the concentration of soluble salts and reduce productivity or make it inviable. We collected 38 soil samples in 22 points at variable depths, normally between 0 to 20 and 30 to $50 \mathrm{~cm}$. The samples were air dried and their chemical and granulometric attributes analyzed. The soil of Golfão Maranhense presents high variability of chemical and granulometric attributes, and is predominant with high exchange capacity, high sum of bases, and high concentration of hydrogen and aluminum. The magnesium concentration predominates in relation to calcium. Even though the majority of soils present clay texture, granulometry is highly variable. Despite the high concentration of magnesium and sodium, the soil flocculation degree is considered high. The soils of Golfão Maranhense are not salinized, but an appropriate management is necessary so not to promote its salinization.

KEYWORDS: hidromorphic soils, flood plains, high clay activity.

\footnotetext{
1 Universidade Federal do Ceará. Email: valladares@ufc.br
} 


\section{INTRODUÇÃO}

A salinização dos solos é um problema global que afeta 950 mha em mais de cem países e recobre mais de $10 \%$ das terras do planeta (Schofield \& Kirkby, 2003). É mais frequente em solos de clima árido ou semi-árido e associada a questáo da desertificação é uma grande preocupação mundial (Mainguet \& Silva, 1998; Symeonakis \& Drake, 2004).

O Estado do Maranháo apresenta quatro unidades geomorfológicas: chapadóes centrais e meridionais; área de transição com relevo residual; colinas terciárias e o Golfão Maranhense, uma regiáo rebaixada e alagadiça dos estuários afogados dos rios Pindaré, Mearim, Itapecuru e Munim (Ab’Saber, 1960). Segundo a classificação de Ab 'Saber (1960), o Golfấo Maranhense é formado por terras rebaixadas, próximas ao mar, onde ocorrem zonas com risco de inundaçáo e presença de solos hidromórficos ou com drenagem impedida e elevados teores de bases trocáveis.

Em função das características edafoclimáticas da região, tais solos devem ser manejados com atenção para evitar a salinização. A salinização ocorre com maior frequencia em regióes tropicais de clima quente e seco, caracterizado por elevadas taxas de evapotranspiração (FAO/UNESCO, 1973). No caso da região do Golfo Maranhense, por apresentarem drenagem com algum impedimento, proximidade com o mar e condiçôes favoráveis a inundação, também ficam sujeitos aos processos de evaporaçáo maior que a precipitaçáo pluviométrica, o que pode elevar as concentraçôes de sais solúveis nos horizontes superficiais.

Os sais solúveis no solo contribuem para a redução do potencial osmótico, dificultando a absorção de água e causando desbalanço de nutrientes nos vegetais cultivados, podendo levar a redução da produtividade ou até mesmo inviabilizá-la (Ruiz et al., 2004). Com base no exposto, este trabalho caracteriza química e granulometricamente os solos representativos do Golfāo Maranhense por suas fragilidades ambientais e propriedades particulares no que se refere aos atributos químicos.

\section{MATERIAL E MÉTODOS}

A área de estudo corresponde aos campos flúvio-marinhos com risco de inundação e presença de solos hidromórficos da regiāo do Golfão Maranhense (Figura 1). O Golfão Maranhense é o acidente geográfico mais importante do litoral do Estado do Maranhão e fica localizado na Amazônia Legal. Geologicamente, a regiáo é constituída por rochas do Terciário, apresentando exposição da Formação Itapecuru; do Grupo Barreiras e predominâncias de sedimentos Quaternários, isto é, depósitos marinhos e flúvio-marinhos do Holoceno e Pleistoceno que tornam expressiva a formaçáo de dunas e vales afogados com presença de mangue (Medeiros,1988).
A vegetação primária da região é caracterizada por floresta Amazônica Maranhense transicional para floresta de babaçu, com muitas áreas ocupadas por vegetaçôes secundárias, que se devem a séculos de ocorrências de desflorestamentos e queimadas sucessivas para agricultura de subsistência. Estas florestas podem ter caráter semidecidual (Embrapa, 1986; Muniz, 2004). Ocorrem também na regiáo áreas com vegetaçâoo de mangue (Embrapa, 1986).

Trata-se de uma extensa planície formada por sedimentos fúvio-marinhos, com cotas altimétricas próximas ao nível do mar. As precipitaçóes pluviométricas apresentam média anual entre 1.800 e 1.900 mm (Embrapa, 1986; Anjos et al., 1995), porém as chuvas sáo concentradas em um período do ano, quando grande parte das planícies fica inundada. Por essa característica, os solos predominantes na regiáo apresentam algum grau de hidromorfismo e são comumente classificados como gleissolos, plintossolos e vertissolos (Embrapa, 1986, Anjos et al., 2007).

Foram coletadas, com auxílio de trado holandês, 38 amostras simples deformadas de solo em 22 pontos amostrais, distribuídos na área de estudo (Tabela 1). A escolha dos locais de amostragem foi por conveniência, devido a grande extensão da área de estudo e objetivando representar a variabilidade de solos. As amostras foram coletadas a profundidades variáveis, normalmente de 0 a 20 e de 30 a $50 \mathrm{~cm}$ de profundidade, de acordo com a presença de um horizonte subsuperficial diagnóstico glei, vértico ou plíntico, isso devido a variaçāo da profundidade de ocorrência dos horizontes subsuperficiais.

A terra fina seca ao ar (TFSA) foi analisada no laboratório da Embrapa Meio Ambiente e foram caracterizadas segundo a metodologia da Embrapa (1997), os seguintes atributos: $\mathrm{pH}$ em água, $\mathrm{pH}$ em $\mathrm{KCl} 1 \mathrm{~N}, \mathrm{~K}^{+}, \mathrm{Na}^{+}, \mathrm{Ca}^{2+}, \mathrm{Mg}^{2+}$, acidez potencial $\left(\mathrm{H}^{+}+\mathrm{Al}^{3+}\right), \mathrm{Al}^{3+}$, Valor T (CTC do solo), CTC da fração argila, Valor S (soma de bases), V\% (saturação por bases), saturação

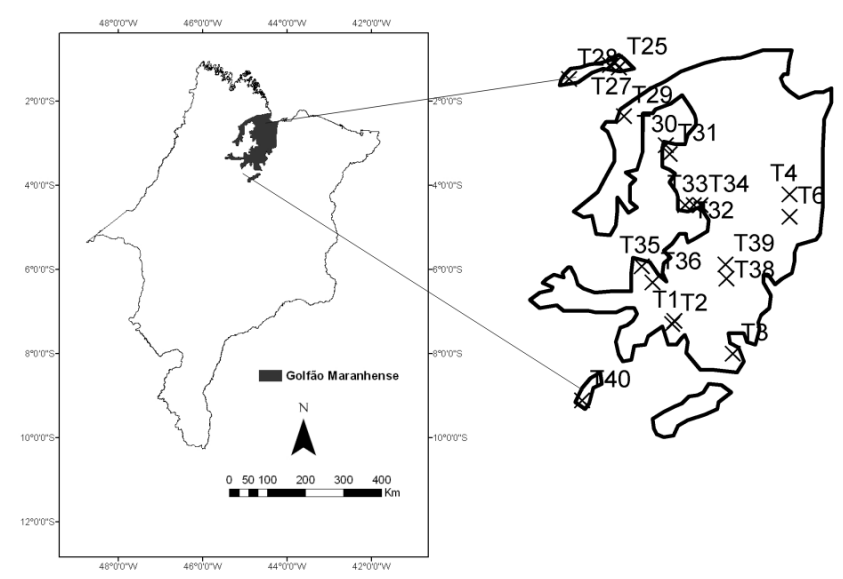

Figura 1 - Localização do Golfão Maranhense no Estado do Maranhão. 
por sódio, carbono orgânico (C), P assimilável, areia fina, areia grossa, silte, argila e grau de floculação.

Os dados foram analisados por estatística descritiva, calcularam-se média, mediana, valor mínimo, valor máximo, desvio padrão e coeficiente de variaçáo. Foram efetuadas análises de correlação de Pearson e interpretaçáo dos dados por meio de diagramas de dispersão. Os coeficientes de correlação tiveram sua significância testada pelo teste t de Student a 5\% de probabilidade.

$\mathrm{Na}$ análise dos componentes principais (ACP) foram calculados os fatores referentes as informaçóes de todas as variáveis pesquisadas. Desse modo cada amostra de solo passa a ser definida por novas variáveis (fatores) o que possibilita a utilizaçáo como ferramenta no agrupamento de variáveis e possíveis correlaçóes.

\section{RESULTADOS E DISCUSSÃO}

Os solos estudados, de forma geral, apresentaram caráter ácido ao se analisar os valores de $\mathrm{pH}$ em água com valores de média e mediana de 4,8 e coeficiente de variaçáo relativamente baixo e igual $14,9 \%$. Segundo o Sistema Brasileiro de Classificação de Solos (Embrapa, 2006), 26,3\% das amostras mostraram-se extremamente ácidas, $52,6 \%$ fortemente ácidas, $18,4 \%$ moderadamente ácidas e apenas uma amostra $(2,6 \%)$ moderadamente alcalina (Tabela 1). Uma amostra coletada a profundidade de $30 \mathrm{a} 60 \mathrm{~cm}$ pôde ser considerada como solo tiomórfico, por apresentar $\mathrm{pH}$ inferior a 3,5 e outra amostra coletada de 40 a $50 \mathrm{~cm}$ apresentou $\mathrm{pH}$ elevado de 7,4. Os valores de $\mathrm{pH}$ em água apresentaram correlação positiva e significativa com os atributos $\mathrm{pH}$ em $\mathrm{KCl}(\mathrm{r}=0,84), \mathrm{Ca}^{2+}$ $(\mathrm{r}=0,47)$, saturaçáo por bases $(\mathrm{r}=0,37)$ e areia grossa $(\mathrm{r}=0,41)$ (Tabela 2). A correlaçấo foi negativa com os atributos acidez potencial $(\mathrm{r}=-0,61), \mathrm{Al}^{3+}(\mathrm{r}=-0,60), \mathrm{C}(\mathrm{r}=-0,37)$ e grau de floculação $(r=-0,68)$.

A correlação positiva dos valores de $\mathrm{pH}$ com os teores de $\mathrm{Ca}^{2+}$ e saturação por bases deve-se a maior proporção de cátions básicos ocupando os sítios de troca dos solos em comparaçáo aos cátions geradores da acidez do solo como $\mathrm{H}^{+}$e $\mathrm{Al}^{3+}$. Maiores valores de acidez potencial e $\mathrm{Al}^{3+}$ nos solos aumentam sua acidez e conseqüente reduçáo do $\mathrm{pH}$, assim como os radicais ácidos da matéria orgânica do solo. Maiores valores de $\mathrm{pH}$ refletem em maior saturação por bases e menores teores de $\mathrm{Al}^{3+}$. Os cátions $\mathrm{Na}^{+}, \mathrm{Mg}^{2+} \mathrm{e} \mathrm{Ca}^{2+}$ podem funcionar como agentes dispersantes da argila e o $\mathrm{Al}^{3+}$ como floculante (Dontsova \& Norton, 2002; Isbell, 2002; Azevedo \& Bonumá, 2004). Estes fenômenos explicam a correlaçáo negativa entre os valores de $\mathrm{pH}$ e o grau de floculaçáo.

Houve elevada correlaçáo positiva e significativa do $\mathrm{pH}$ em água e em KCl. A correlação do $\mathrm{pH}$ com a concentraçấo de $\mathrm{Al}^{3+}$ e com a acidez potencial demonstra que as variáveis são inversamente proporcionais, isto é, com aumento do $\mathrm{pH}$ ocorre diminuiçáo de $\mathrm{Al}^{3+}$ e da acidez potencial, sendo que a linha de tendência exponencial foi a de melhor representatividade. Segundo a literatura os teores $\mathrm{de}^{3 l^{3+}} \mathrm{em}$ solos com pH superiores a 5,5 tendem a zero (Nachtigall \& Vahl, 1989; Nascimento, 1989; Pereira et al., 1998). Em várias amostras com $\mathrm{pH}$ superior a 5 os teores de $\mathrm{Al}^{3+}$ são superiores a $1 \mathrm{cmol}^{\mathrm{kg}^{-1}}$, estes resultados demonstram a alta disponibilidade de $\mathrm{Al}^{3+}$ nos solos estudados, indicando esta propriedade ser características dos solos estudados e se diferenciar dos resultados apresentados na literatura para solos de outras regióes. Somente uma amostra com pH superior a 7,0 apresentou teores do elemento tendendo a zero.

Quanto a acidez potencial, 2,6\% das amostras estáo entre 0 e $5 \mathrm{cmol}_{\mathrm{c}} \mathrm{kg}^{-1}, 44,7 \%$ entre 5 e $10 \mathrm{cmol}_{\mathrm{c}} \mathrm{kg}^{-1}, 34,2 \%$ entre 10 e $15 \mathrm{cmol}_{c} \mathrm{~kg}^{-1}$ e $18,4 \%$ são maiores que $15 \mathrm{cmol}_{c} \mathrm{~kg}^{-1}$, a média foi de $11,8 \mathrm{cmol}_{\mathrm{c}} \mathrm{kg}^{-1} \mathrm{e}$ a mediana de $10,6 \mathrm{cmol}_{\mathrm{c}} \mathrm{kg}^{-1}$, com elevado coeficiente de variação de $51,0 \%$. Os resultados demonstram que na área de estudo solos com baixos valores de acidez potencial, porém a grande maioria das amostras apresenta teores muito elevados deste atributo. A acidez potencial apresentou correlação positiva e significativa a 5 $\%$ com os atributos $\mathrm{Al}^{3+}(\mathrm{r}=0,91)$, carbono $(\mathrm{r}=0,59)$, argila $(\mathrm{r}=0,52)$ e grau de floculação $(\mathrm{r}=0,40)$. A correlaçáo é negativa com a saturação por bases $(\mathrm{r}=-0,58)$, a areia fina e a areia total ( $r=-0,37$ e $-0,38$, respectivamente).

$\mathrm{O} \mathrm{Al}^{3+}$ em 7,8\% das amostras apresenta teores entre $0 \mathrm{e}$ $0,5 \mathrm{cmol} \mathrm{kg}^{-1}, 31,5 \%$ entre 0,5 e $2 \mathrm{cmol}_{\mathrm{c}} \mathrm{kg}^{-1}, 21 \%$ entre 2 e $4 \mathrm{cmol}_{\mathrm{c}} \mathrm{kg}^{-1}$ e $39,4 \%$ possuem valor maior que $4 \mathrm{cmol}_{\mathrm{c}}$ $\mathrm{kg}^{-1} \mathrm{o}$ que indica altas concentraçôes e caráter alumínico ou alítico (Embrapa, 2006), uma vez que as amostras apresentam alta CTC em sua totalidade (Tabela 1). Essas concentraçóes elevadas justificam a grande acidez do solo mesmo com altos teores e saturação por bases. Os teores de $\mathrm{Al}^{3+}$ apresentaram correlaçáo positiva e significativa a $5 \%$ com os atributos carbono $(\mathrm{r}=0,34)$, argila $(\mathrm{r}=0,35)$ e grau de floculação $(\mathrm{r}=0,41)$, os altos teores de $\mathrm{Al}^{3+}$ podem explicar o alto grau de floculação dos solos apesar dos elevados teores de $\mathrm{Na}^{+}$e $\mathrm{Mg}^{2+}$, atributos que podem causar a dispersão da argila. A correlação é negativa com a saturação por bases $(r=-0,65)$.

Em aproximadamente $50 \%$ dos locais amostrados observase redução do $\mathrm{pH}$ em profundidade paralelamente ao aumento dos teores de $\mathrm{Al}^{3+}$. Esse aumento da acidez em profundidade, decorrente possivelmente do processo de ferrólise (Brinkman, 1970), é freqüentemente observado em solos sujeitos ao encharcamento no período chuvoso. Este comportamento foi verificado em solos do Município de Pinheiro, MA (Anjos et al., 2007), e em solos plínticos desenvolvidos do Arenito Bauru em São Paulo (Coelho \& Vidal-Torrado, 2003).

Em relação aos teores de $\mathrm{K}^{+}, 42 \%$ das amostras estão abaixo de $0,7 \mathrm{cmol}_{\mathrm{c}} \mathrm{kg}^{-1}, 47,4 \%$ estâo entre 0,7 e $1,5 \mathrm{cmol}_{c}$ 


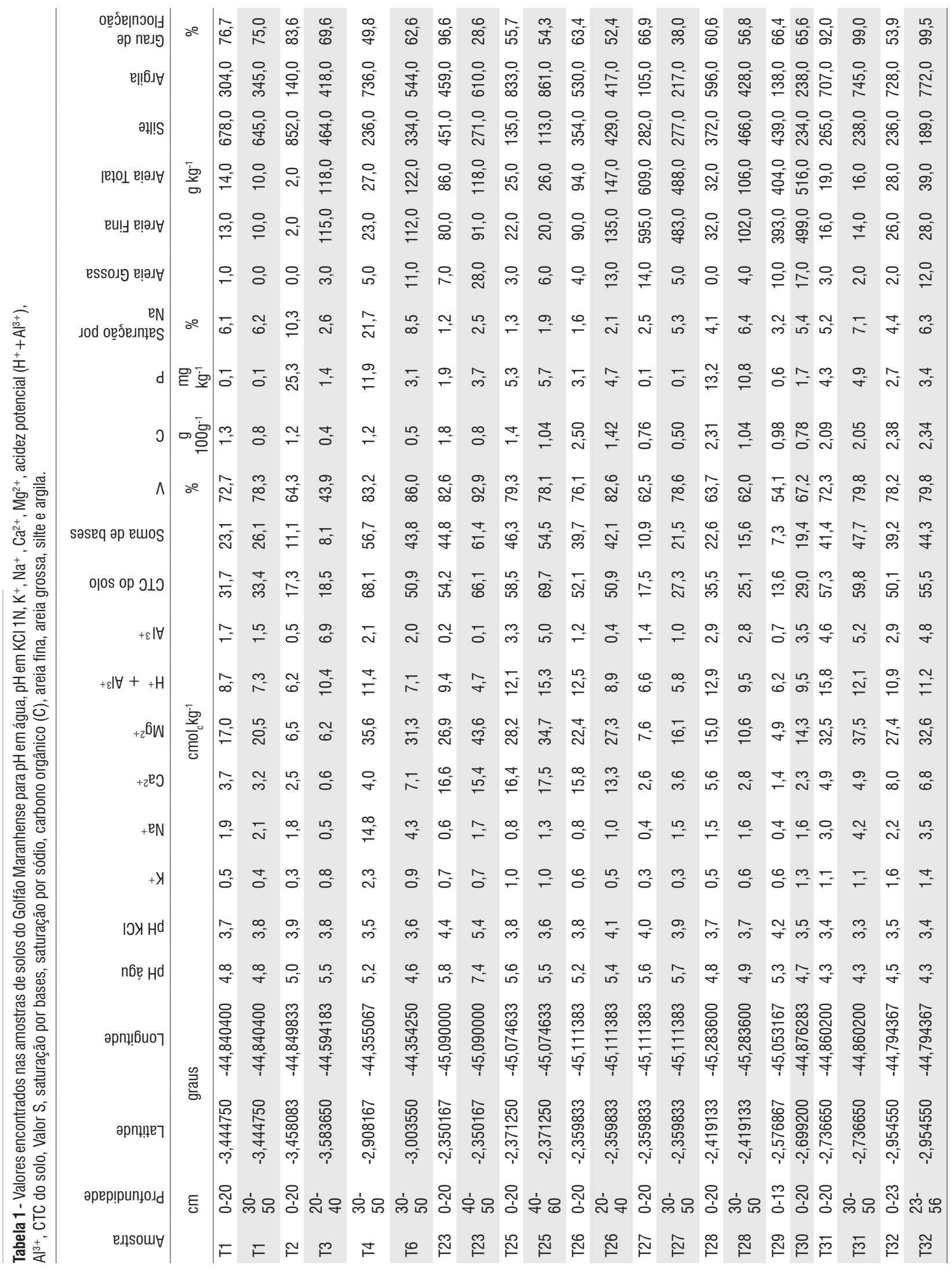




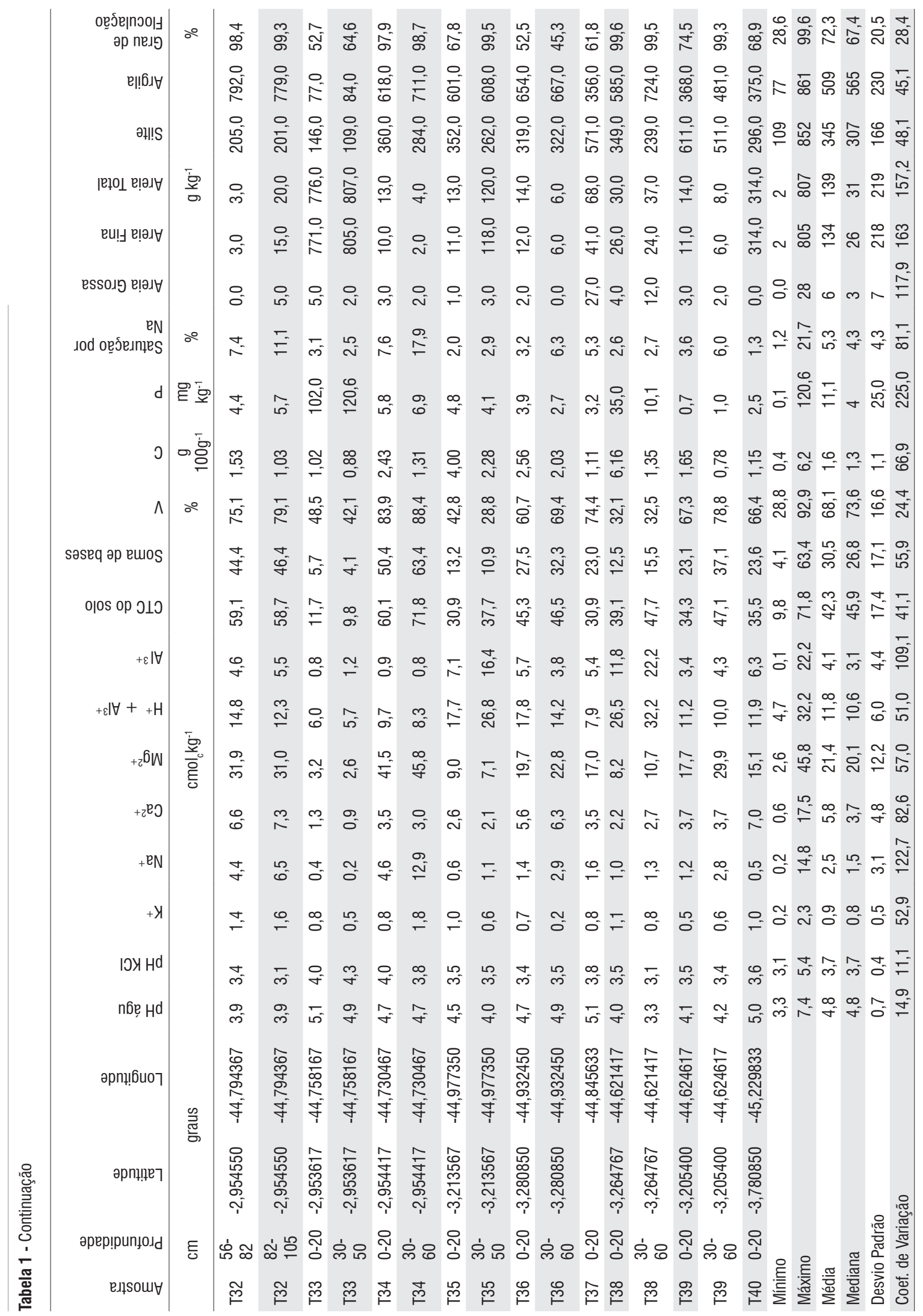




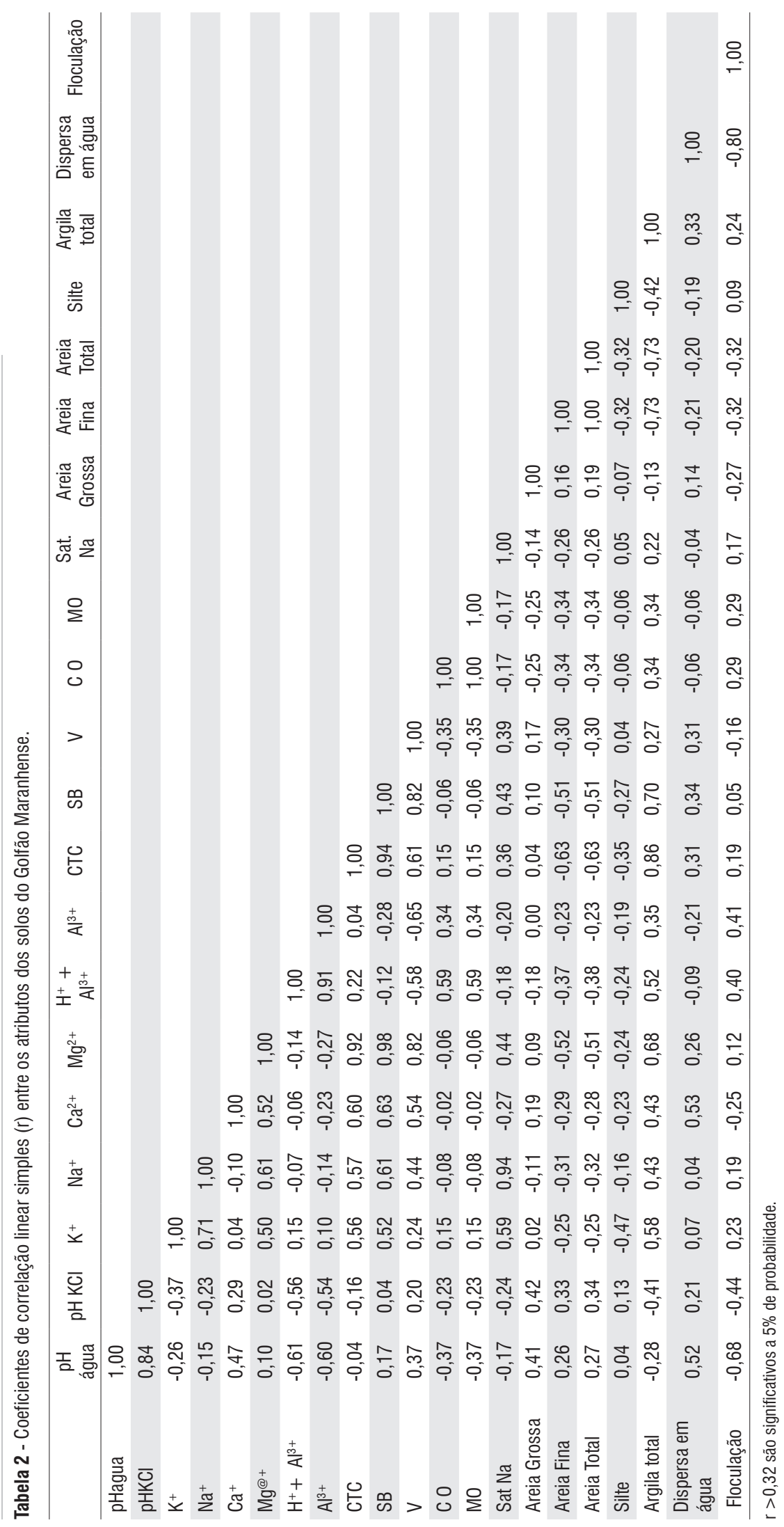


$\mathrm{kg}^{-1}$ e 10,5\% entre 1,5 e 3,0 cmol $\mathrm{kg}^{-1}$. Apresentam correlaçáo positiva e significativa a $5 \%$ com $\mathrm{Na}^{+}(\mathrm{r}=0,71), \mathrm{Mg}^{2+}(\mathrm{r}=0,50)$, CTC do solo $(r=0,56)$, soma de bases $(r=0,52)$ e argila $(r=0,58)$ e negativa com silte $(r=-0,47)$. A grande maioria dos locais apresenta elevados teores de $\mathrm{K}^{+}$, segundo a classificação de Raij et al (1997), com média de $09 \mathrm{cmol}_{\mathrm{c}} \mathrm{kg}^{-1}$, mediana de 0,8 cmol $\mathrm{ckg}^{-1}$ e coeficiente de variação alto de $52,9 \%$.

Os teores de $\mathrm{Na}^{+}$em $26,3 \%$ dos locais apresentaram valores de 0 a $1 \mathrm{cmol}_{c} \mathrm{~kg}^{-1}, 39,4 \%$ de 1 a $2 \mathrm{cmol}_{\mathrm{c}} \mathrm{kg}^{-1}, 15,7 \%$ de 2 a $4 \mathrm{cmol}_{\mathrm{c}} \mathrm{kg}^{-1} \mathrm{e} 18,4 \%$ apresentaram valor maior que $4 \mathrm{cmol}_{\mathrm{c}}$ $\mathrm{kg}^{-1}$, com média de $2,5 \mathrm{cmol}_{\mathrm{c}} \mathrm{kg}^{-1}$, mediana de $1,5 \mathrm{cmol}_{\mathrm{c}} \mathrm{kg}^{-1}$ e coeficiente de variação muito alto de $123 \%$. A concentração de $\mathrm{Na}^{+}$superior a de $\mathrm{K}^{+}$é muito negativa no que se refere a produtividade dos solos, pois o $\mathrm{Na}^{+}$não é considerado nutriente essencial aos vegetais e causa problemas de dispersão da argila. $\mathrm{O} \mathrm{Na}^{+}$apresenta correlação positiva e significativa a $5 \%$ com $\mathrm{Mg}^{2+}(\mathrm{r}=0,61)$, CTC do solo $(\mathrm{r}=0,57)$, soma de bases $(r=0,61)$, saturação por bases $(0,44)$ e argila $(r=0,43)$. A correlação foi negativa com areia total $(r=-0,32)$.

A saturação por sódio indica que $65,7 \%$ dos locais encontram-se entre 0 e 6\%, 28,9\% entre 6 e 15\% (caráter solódico, segundo Embrapa, 2006) e 5,2\% tem caráter sódico ( $>15 \%$, segundo Embrapa, 2006). Tais resultados indicam que devem ser tomados cuidados no manejo para evitar ainda mais a elevação dos teores do elemento nos solos estudados. A saturação por sódio teve média de $5,3 \%$, mediana de 4,3 e coeficiente de variação elevado de $81,1 \%$.

$\mathrm{O} \mathrm{Ca}^{2+}$ em $10,5 \%$ dos locais está entre 0 e $2 \mathrm{cmol}_{\mathrm{c}} \mathrm{kg}^{-1}$, em $42,1 \%$ entre 2 e $4 \mathrm{cmol}_{c} \mathrm{~kg}^{-1}$, em $31,5 \%$ entre 4 e $8 \mathrm{cmol}_{c}$ $\mathrm{kg}^{-1}$ e em $15,7 \%$ apresentaram valor maior que $8 \mathrm{cmol}_{\mathrm{c}} \mathrm{kg}^{-1}$. Esses teores apresentaram correlaçấo positiva e significativa a $5 \%$ com $\mathrm{Mg}^{2+}(\mathrm{r}=0,52)$, CTC do solo $(\mathrm{r}=0,60)$, soma de bases $(r=0,63)$, saturaçáo por bases $(r=0,54)$ e argila $(r=0,43)$. A grande maioria dos locais apresenta $\mathrm{Ca}^{2+}$ elevado, segundo a classificação de Raij et al (1997), o que indica não haver deficiências para as plantas cultivadas (média de $5,8 \mathrm{cmol}_{c}$ $\mathrm{kg}^{-1}$, mediana de $3,7 \mathrm{cmol}_{\mathrm{c}} \mathrm{kg}^{-1}$ e coeficiente de variação elevado de 82,6\%).

Os valores de $\mathrm{Mg}^{2+}$ estão assim distribuídos: $23,6 \%$ entre 0 e $10 \mathrm{cmol} \mathrm{ckg}_{\text {c }}^{-1} ; 26,3 \%$ entre 10 e $20 \mathrm{cmol} \mathrm{kg}_{\text {c }}{ }^{-1} ; 21 \%$ entre 20 e $30 \mathrm{cmol}_{\mathrm{c}} \mathrm{kg}^{-1} \mathrm{e} 28,9 \%$ maior que $30 \mathrm{cmol}_{\mathrm{c}} \mathrm{kg}^{-1}$. Todas os locais apresentam teores considerados altos de $\mathrm{Mg}^{2+}$ e superiores aos de $\mathrm{Ca}^{2+}$, com média de $21,4 \mathrm{cmol}_{\mathrm{c}} \mathrm{kg}^{-1}$, mediana de $20,1 \mathrm{e}$ coeficiente de variação de $57 \%$.. Tal característica demonstra desequilíbrio entre estes cátions e que pode ser prejudicial para a nutrição mineral das plantas cultivadas, resultados semelhantes foram verificados em trabalhos com solos maranhenses (Anjos et al., 2007) e no semiárido nordestino (Oliveira et al., 2003). Segundo estes últimos autores $\mathrm{Ca}^{2+}$ inferior a $\mathrm{Mg}^{2+}$ está relacionado a maior solubilidade do $\mathrm{Mg}^{2+}$ e ao material de origem com influência marinha. Os teores de $\mathrm{Mg}^{2+}$ têm correlação positiva e significativa a 5\% com os atributos CTC do solo $(r=0,92)$, soma de bases $(r=0,98)$, saturação por bases $(r=0,82)$, saturação por sódio $(r=0,44)$ e argila $(r=0,68)$. A correlaçấo foi negativa com a areia fina e a areia total $(\mathrm{r}=-0,52$ e $-0,51$, respectivamente).

Quanto aos valores de CTC do solo, 15,7\% das amostras encontram-se entre 0 e $20 \mathrm{cmol}_{\mathrm{c}} \mathrm{kg}^{-1}, 31,7 \%$ entre 20 e 40 cmol $\mathrm{kg}^{-1}, 39,4 \%$ entre 40 e $60 \mathrm{cmol} \mathrm{kg}_{\mathrm{c}} \mathrm{kg}^{-1}$ e 13,1\% são maiores que $60 \mathrm{cmol}_{\mathrm{c}} \mathrm{kg}^{-1}$, com média de $42,3 \mathrm{cmol}_{\mathrm{c}} \mathrm{kg}^{-1}$, mediana de

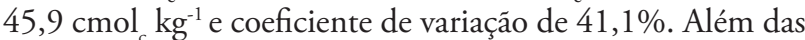
já mencionadas, a CTC do solo apresentou correlação positiva e significativa a $5 \%$ com os atributos soma de bases $(r=0,94)$, saturação por bases $(r=0,61)$, saturaçáo por sódio $(r=0,36)$ e argila $(r=0,86)$. A correlação foi negativa com areia fina, areia total $(\mathrm{r}=-0,63)$ e silte $(\mathrm{r}=-0,35)$. O carbono não apresentou correlação com a CTC do solo. A CTC da fração argila apresentou valor mínimo de $44,3 \mathrm{cmol}_{\mathrm{c}} \mathrm{kg}^{-1}$, o que indica que os solos têm atividade alta (Ta) segundo (Embrapa, 2006).

$\mathrm{Na}$ soma de bases, $10,5 \%$ dos valores estáo entre 0 e 10 $\mathrm{cmol}_{c} \mathrm{~kg}^{-1}, 42,1 \%$ entre 10 e $30 \mathrm{cmol}_{\mathrm{c}} \mathrm{kg}^{-1}, 34,2 \%$ entre 30 e $50 \mathrm{cmol}_{c} \mathrm{~kg}^{-1}$ e $13,1 \%$ são maiores que $50 \mathrm{cmol}_{\mathrm{c}} \mathrm{kg}^{-1}$, com média de $30,5 \mathrm{cmol}_{\mathrm{c}} \mathrm{kg}^{-1}$, mediana de $26,8 \mathrm{cmol}_{\mathrm{c}} \mathrm{kg}^{-1} \mathrm{e}$ coeficiente de variação de $55,9 \%$. Além das já mencionadas a soma de bases apresenta correlação positiva e significativa a $5 \%$ com os atributos saturação por bases $(\mathrm{r}=0,82)$, saturação por sódio $(r=0,43)$ e argila $(r=0,70)$. A correlação é negativa com areia fina e areia total $(r=-0,63)$.

$\mathrm{Na}$ saturaçáo por bases, 7,8\% estáo entre 0 e 35\%, consideradas hiperdistróficas (Embrapa, 2006); 10,5\% entre 35 e 50\%, mesodistróficas; $34,2 \%$ entre 50 e $75 \%$, mesoeutróficas; e $47,3 \%$ são maiores que $75 \%$ de saturação por bases, ou seja, são hipereutróficas. O valor médio foi de $68,1 \%$ e a mediana de $73,6 \%$, com coeficiente de variação de $24,4 \%$, o que indica variabilidade inferior a da soma de bases. Trabalhos com plintossolos da região meio-norte e da ilha de Marajó verificaram baixa saturação por bases e altos teores de $\mathrm{Al}^{3+}$ com alta saturação por alumínio (Santos \& Batista, 1996; Rêgo, 1986). Anjos et al. (2007) trabalhando com solos de Pinheiro, MA, encontraram maior saturação por bases nos horizontes superficiais, o que coincide com o presente trabalho. A saturação por bases, além das correlações já mencionadas, apresentou correlaçấo positiva e significativa a $5 \%$ com a saturaçáo por sódio $(r=0,39)$ e negativa com carbono $(\mathrm{r}=-0,35)$.

Os teores de carbono foram assim distribuídos: 26,3\% dos valores estão entre 0 e $10 \mathrm{~g} \mathrm{~kg}^{-1}, 34,2 \%$ estão entre $10 \mathrm{e}$ $15 \mathrm{~g} \mathrm{~kg}^{-1}, 7,8 \%$ entre 15 e $20 \mathrm{~g} \mathrm{~kg}^{-1}$ e $31,5 \%$ apresentam teor maior que $20 \mathrm{~g} \mathrm{~kg}^{-1}$. Esses teores são considerados baixos para solos hidromórficos, isto provavelmente se deve aos vários meses de estiagem o que diminui a sua saturaçáo com água. Apresentaram média de 1,6\% e mediana de 1,3\% com 

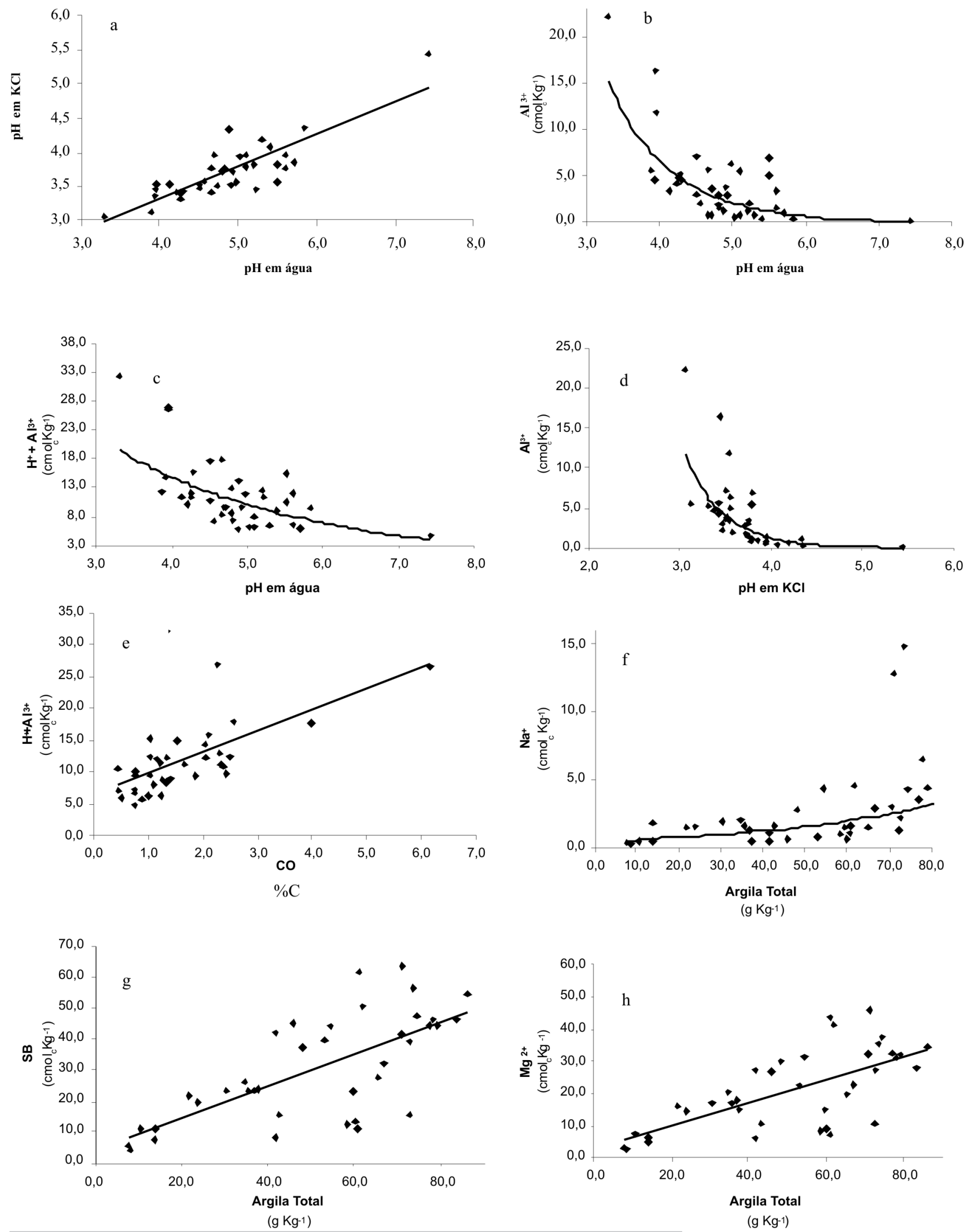

Figura 2 - Diagramas de dispersão entre atributos dos solos do Golfão Maranhense. 
alto coeficiente de variação de $66,9 \%$. O carbono, além das correlaçôes já mencionada,s apresentou correlação positiva e significativa a 5\% com os teores de argila $(\mathrm{r}=0,34)$. E negativa com os teores de areia $(\mathrm{r}=-0,34)$.

O P, 76,3\% dos valores estâo entre 0 e $6 \mathrm{mg} \mathrm{kg}^{-1}, 13,1 \%$ entre 6 e $15 \mathrm{mg} \mathrm{kg}^{-1}, 5,2 \%$ entre 15 e $40 \mathrm{mg} \mathrm{kg}^{-1} \mathrm{e}$ 5,2\% acima de $40 \mathrm{mg} \mathrm{kg}^{-1}$, estes resultados indicam possíveis deficiência do nutriente para as plantas cultivadas, pois a média foi de 11,1 , a mediana de 4,0 e elevado coeficiente de variação, demonstrando o motivo pelo qual os valores da média foram táo mais elevados que da mediana.

A grande maioria dos solos apresentou textura argilosa a muito argilosa $(76,2 \%)$, sendo que $10,5 \%$ tinha textura média, $7,8 \%$ siltosa e $5,2 \%$ textura arenosa, de acordo com Embrapa (2006) e Santos et al. (2005). A predominância da fração argila nos solos, pode dificultar a permeabilidade, diminuindo sua condutividade hidráulica, ainda mais com a ocorrência de argilas expansíveis (Anjos et al., 2007), que ao diminuir a agregação das partículas, leva a uma estrutura maciça. Tal condição dificulta a respiração e o crescimento radicular, sendo um forte fator limitante ao cultivo de muitas espécies.

A correlação da argila com $\mathrm{Na}^{+}$foi positiva e significativa $(r=0,43)$ e a correlaçấo da argila com a matéria orgânica foi positiva e baixa. Já as correlaçôes da argila com a soma de bases $(\mathrm{r}=0,70)$ e com $\mathrm{Mg}(\mathrm{r}=0,68)$ são positivas e muito altas, o que indica alta interação entre esses atributos.

Os teores de silte predominam nas amostras em relação aos de areia. Seus teores tiveram correlação negativa com os teres de argila $(r=-0,42)$ e com o grau de floculação $(r=-0,32)$.

Observa-se o predomínio da fração areia fina em relação a areia grossa. A areia total teve correlaçáo alta e positiva com a fraçáo areia fina $(r=0,99)$ e negativa com os teores de silte $(\mathrm{r}=-0,32)$ e argila $(\mathrm{r}=-073)$.

Do grau de floculação, $10,5 \%$ dos locais apresentam de 0 a $50 \%, 52,6 \%$ têm de 50 a $75 \%$ e $36,8 \%$ com mais de $75 \%$ de grau floculação. A média encontrada foi $72,3 \%$. Apesar do $\mathrm{Na}^{+}$e $\mathrm{Mg}^{2+}$ causarem dispersão das argilas e redução do grau de floculação (Emerson e Chi, 1977; Zhang e Norton, 2002; Ruiz et al., 2004) não se observou esta característica nos solos do Golfão Maranhense, eles apresentam alta floculação. Isto está de acordo com os plintossolos maranhenses que possuem que possuem maior floculação nos horizontes superficiais (Anjos et al., 1995).

A condutividade elétrica no extrato de saturação foram baixos (próximos a zero), o que indica ausência de problemas de salinidade nos solos, apesar dos altos teores de bases; porém há a ocorrência de sodicidade em $37 \%$ das amostras e de alcalinidade em uma das amostras.

\section{ANÁLISE DOS COMPONENTES PRINCIPAIS}

$\mathrm{Na}$ ACP são calculados os fatores que se referem a informaçóes de todas as amostras pesquisadas, no presente caso todos os atributos dos solos avaliados, cada atributo do solo, que era definido pelas 38 amostras, passa a ser definido pelas novas variáveis (fatores) o que possibilita sua localização como um ponto em um gráfico bidimensional ou tridimensional, e quanto mais próximos forem os pontos maiores tenderão a ser suas semelhanças, podendo ser utilizada como ferramenta na correlação entre variáveis.

Os resultados da ACP são apresentados na Tabela $3 \mathrm{e}$ Figura 3. De acordo com os resultados dos "eigenvalues", os três primeiros componentes principais ou fatores foram considerados (representados por F1, F2 e F3), pois explicam $68,4 \%$ da variação. Há associaçấo positiva entre $\mathrm{K}^{+}, \mathrm{Na}^{+}$, $\mathrm{Mg}^{2+}, \mathrm{Ca}^{2+}$, CTC, soma de bases, V\% e argila total (elevados valores positivos no $\mathrm{F} 1$ ) e negativa com $\mathrm{P}$, areia fina e areia total (valores mais negativos no $\mathrm{F} 1$ ). Os valores de $\mathrm{pH}$ em água, $\mathrm{pH}$ em $\mathrm{KCl}$ e V\% foram positivos e altos em $\mathrm{F} 2$ indicando associação positiva, sendo negativos neste fator os atributos acidez potencial, $\mathrm{Al}^{3+}$ e carbono orgânico com associação negativa. Em F3 observou-se associação positiva entre $\mathrm{Ca}^{2+} \mathrm{e}$ argila dispersa, sendo negativa para os teores de $\mathrm{Na}^{+}$e saturaçáo

Tabela 3 - Fatores calculados pela análise dos componentes principais com base nos atributos dos solos do Golfão Maranhense.

\begin{tabular}{lccc}
\hline Atributos & Fator 1 & Fator 2 & Fator 3 \\
\hline pHagua & $-0,118$ & 0,811 & 0,392 \\
$\mathrm{pHKCl}$ & $-0,279$ & 0,696 & 0,350 \\
\hline $\mathrm{K}^{+}$ & 0,630 & $-0,127$ & $-0,445$ \\
\hline $\mathrm{Na}^{+}$ & 0,658 & 0,970 & $-0,664$ \\
$\mathrm{Ca}^{2+}$ & 0,481 & 0,391 & 0,630 \\
$\mathrm{Mg}^{2+}$ & 0,886 & 0,339 & $-0,440$ \\
$\mathrm{H}^{+}+\mathrm{Al}^{3+}$ & 0,193 & $-0,876$ & 0,228 \\
\hline $\mathrm{Al}^{3+}$ & 0,170 & $-0,814$ & 0,112 \\
$\mathrm{CTC}^{+}$ & 0,953 & 0,560 & 0,930 \\
\hline $\mathrm{SB}$ & 0,902 & 0,365 & 0,150 \\
$\mathrm{~V}$ & 0,626 & 0,691 & $-0,510$ \\
\hline $\mathrm{C} \mathrm{O}$ & 0,171 & $-0,680$ & 0,325 \\
\hline $\mathrm{P}$ & $-0,532$ & $-0,400$ & $-0,257$ \\
\hline Sat Na & 0,492 & 0,119 & $-0,766$ \\
\hline Areia Grossa & $-0,480$ & 0,390 & 0,233 \\
\hline Areia Fina & $-0,766$ & 0,293 & $-0,231$ \\
\hline Areia Total & $-0,763$ & 0,304 & $-0,222$ \\
\hline Silte & $-0,202$ & 0,510 & 0,570 \\
\hline Argila total & 0,880 & $-0,310$ & 0,157 \\
\hline Dispersa em água & 0,331 & 0,342 & 0,447 \\
\hline
\end{tabular}



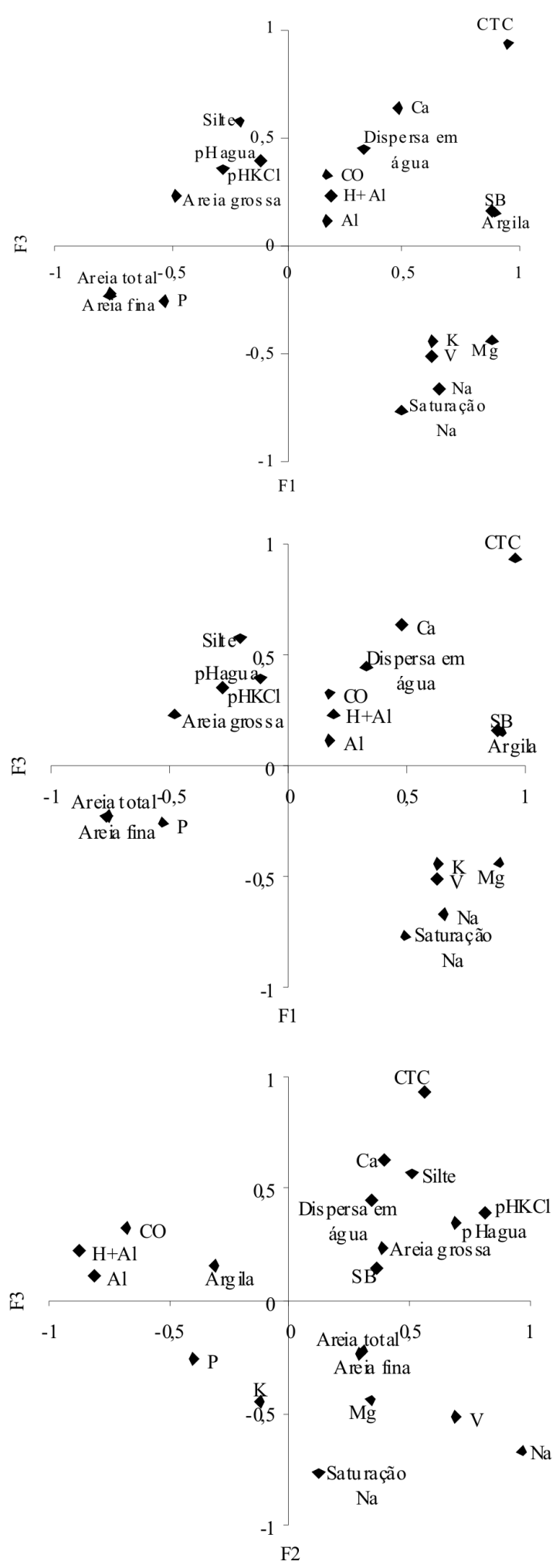

Figura 3 - Agrupamento dos atributos dos solos do Golfão Maranhense com base nos fatores 1, 2 e 3 calculados pela análise dos componentes principais. por este elemento. Verificou-se ambiguidade nos fatores F1 e F3 para $\mathrm{Ca}^{2+}$ e $\mathrm{Na}^{+}$e nos F1 e F2 para V\%.

\section{CONCLUSÕES}

Apesar de não apresentarem problemas de salinidade, as condiçóes e características dos solos estudados indicam uma grande propensão ao processo de acumulação de sais, principalmente se o manejo for inadequado. $\mathrm{O}$ uso incorreto da irrigação (uso de água com alta concentração de sais, e quantidade de água inadequada) associado a condições propícias como deficiência de drenagem, geram, freqüentemente, problemas para o cultivo nesses solos. $\mathrm{O}$ sucesso da agricultura irrigada depende, além da qualidade da água fornecida às plantas, da drenagem da área e do manejo da fertilidade do solo (Heck et al., 2003; Lozovitskii, 2003; Chaves et. al, 2004).

Barreto (2001), afirma que o principal problema ambiental causado pela má condução da irrigação e que atinge os perímetros irrigados do Nordeste é justamente a degradação de extensas áreas pelo processo físico-químico da salinização. No manejo dos solos do Golfão Maranhense, devem ser tomadas precauçôes para evitar o desencadeamento desse processo. É importante destacar que os solos do Golfão Maranhense náo se encontram salinizados.

\section{AGRADECIMENTOS}

Ao SIFEMA pelo financiamento do projeto, ao CNPq pela bolsa de iniciação científica do programa PIBIC.

\section{BIBLIOGRAFIA CITADA}

AB 'Saber, A. N. 1960. Contribuição à geomorfologia do Estado do Maranhão. Notícia Geomorfológica, 3(5): 35-45.

Anjos, L.H.C.; Pereira, M.G.; Pérez, D.V.; Ramos, D.P. 2007. Caracterização e classificação de Plintossolos no Município de Pinheiro-MA. Revista Brasileira de Ciência do Solo, 31(5):10351044.

Anjos, L.H.C.; Franszmeier, D.P.; Schulze, D.G. 1995. Formation of soils with plinthite on a toposequence in Maranhão State, Geoderma, 64: 257-279.

Barreto, A. N. 2001. Eficiência global do uso de água na agricultura irrigada. In: Simpósio Brasileiro de Recursos Hídricos, 14; Simpósio de Hidráulica e Recursos Hídricos dos países de língua oficial portuguesa, 5. 2001, Aracajú. Anais.Aracajú: Associação Brasileira de Recursos Hídricos, 2001. Meio virtual: CD rom

Azevedo, A.C.; Bonumá, A.S. 2004. Partículas coloidais, dispersão e agregação em latossolos. Ciência Rural, 34(2): 609-617.

Brinkman, R. 1970. Ferrolysis, a hydromorphic soil forming process. Geoderma, 3(3): 199-206.

Chaves, L.H.G.; Tito, G.A.; Chaves, I.B.; Luna, J.G.; Silva, P.C.M. 2004. Propriedades químicas do solo aluvial da ilha de assunção - Cabrobó Pernambuco. Revista Brasileira de Ciência do Solo, 28(3):431-437. 
Coelho, M.R.; Vidal-Torrado, P. Caracterização e gênese de perfis plínticos desenvolvidos de arenito do Grupo Bauru. I-Química. Revista Brasileira de Ciência do Solo, 27(3): 483-494.

Dontsova, K.M.; Norton, L.D. 2002. Clay dispersion, infiltration, and erosion as influenced by exchangeable $\mathrm{Ca}$ and $\mathrm{Mg}$. Soil Science, 167(3):184-193.

Emerson, W.W.; Chi, C.L. 1977. Exchangeable calcium, magnesium and sodium and the dispersion of illites in water. Australian Journal of Soil Research, 15(3): 255-262.

EMPRESA BRASILEIRA DE PESQUISA AGROPECUÁRIA EMBRAPA 1997. Manual de métodos de análises de solo. Centro Nacional de Pesquisa de Solos, RJ, Brasil, 212pp.

EMPRESA BRASILEIRA DE PESQUISA AGROPECUÁRIA - EMBRAPA 1986. Serviço Nacional de Levantamento e Conservação de Solos. Boletim de Pesquisa, 35. Levantamento exploratório-reconhecimento de solo do Estado do Maranhão, 2.

EMPRESA BRASILEIRA DE PESQUISA AGROPECUÁRIA EMBRAPA 2006. Sistema brasileiro de classificação de solo. Centro Nacional de Pesquisa de Solos, RJ, Brasil, 306pp.

FAO/UNESCO, 1973. Irrigation, drainage and salinity. An international sourcebook. HUTCHINSON/FAO/UNESCO, Paris, France, 529pp.

Heck, R.J.; Tiessen, H,; Salcedo, I.H.; Santos, M.C. 2003. Soil chemical changes under irrigated mango production in the central Sáo Francisco river valley. Journal Environmental Quality, 32(4):1414-1421.

Isbell, R.F. 2002. The Australian soil classification. CSIRO, Collingwood, Austrália, 144pp.

Lozovitskii, P.S. 2003. The effect of irrigation water mineralization and the irrigation period on salinization of chernozems. Eurasian Soil Science, 36(5):550-560.

Mainguet, M.; Silva, G.G. 1998. Desertification and drylands development: what can be done? Land Degradation of Development, 9(5):375-382.

Medeiros, T.C.C. 1988. Contribuição ao estudo a fisiografia de mesolitoral do Golfã̃o Maranhense. Boletim LaboHidro 8(1): 81-96.

Muniz, F.H. 2004. A vegetação da regiáo de transição entre a Amazônia e o Nordeste, diversidade e estrutura. In: MOURA, E.G., coord. Agroambientes de transição entre o trópico e o semiárido do Brasil. Universidade Estadual do Maranhão, São Luis, Maranhão. p.53-69.

Nachtigall, G.R.; Vahl, L.C. 1989. Parâmetros relacionados à acidez em solos da região sul do Rio Grande do Sul. Revista brasileira de Ciência do Solo, 13(2): 139-143.

Nascimento, R.A. de M. 1989. Correlação entre o valor Ki e outras variáveis em latossolos. Itaguaí, Brasil. Tese de Mestrado, Universidade Federal Rural do Rio de Janeiro, Rio de Janeiro. $165 \mathrm{pp}$.
Oliveira, L.B.; Ribeiro, M.R.; Ferra, F.B.; Jacomine, P.K.T. 2003. Classsificação de solos planossólicos do sertão do Araripe (PE). Revista Brasileira de Ciência do Solo, 27(4):685-693.

Pereira, M.G.; Valladares, G.S.; Souza, J.M.P.F.; Pérez, D.V.; Anjos, L.H.C. 1998. Parâmetros relacionados à acidez em solos do Estado do Rio de Janeiro. Rio de Janeiro: Embrapa CNPS, (Circular Técnica).

Raij, B. Van; Cantarella, H.; Quaggio, J. A.; Furlani, A. M. C. 1997. Recomendaçóes de adubação e calagem para o Estado de São Paulo. Instituto Agronômico/Fundação IAC. Boletim técnico 100,. 2:285.

Ramos, D.P.; Anjos, L.H.C. 1985. Caracterização de solos afetados por sais em condiçóes não-hidromórficas da região de Campos (RJ). Revista Brasileira de Ciência do Solo, 9(2):122-129.

Rêgo, R.S. 1986. Caracterização e gênese de solos com plintita na Ilha de Marajó. Rio de Janeiro, Brasil. Tese de Mestrado, Universidade Federal Rural do Rio de Janeiro, Rio de Janeiro. 156pp.

Ruiz, H.A.; Sampaio, R.A.; Oliveira, M.; Venegas, V.H.A.. 2004. Características químicas de solos salino-sódicos submetidos a parcelamento da lâmica de lixiviação. Pesquisa Agropecuária Brasileira, 39(11): 1119-1126.

Santos, M.C.; Batista, M. 1996. Avaliaçōes física, química e mineralógica em solos plínticos da região meio-norte do Brasil, submetidos a teste de umidecimento e secagem. Revista Brasileira de Ciência do Solo, 20(1):21-31.

Santos, R.D.; Lemos, R.C.; Santos, H.G.; Ker, J.C.; Anjos, L.H.C. 2005. Manual de descrição e coleta de solo no campo. Sociedade Brasileira de Ciência do Solo. 92p.

Schofield, R.V.; Kirkby, M.J. 2003. Application of salinization indicators and initial development of potential global soil salinization scenario under climatic change. Global Biogeochemical Cycles, 17(3):1-13.

Symeonakis, E.; Drake, N. 2004. Monitoring desertification and land degradation over sub-Saharan Africa. International Journal of Remote Sensing, 25(3):573-592.

Zhang, X.C.; Norton, L.D. 2002. Effect of exchangeable Mg on saturated hydraulic conductivity, disaggregation and clay dispersion of disturbed soils. Journal of Hydrology, 260(14):194-205

Recebido em 24/10/2008

Aceito em 14/06/2009 
